\title{
A política desenvolvimentista para a Amazônia: implementação, objetivos e o revés da SPVEA (1953-1966)
}

Carlos Eugênio Renha*

\begin{abstract}
RESUMO
O governo federal criou a Superintendência do Plano de Valorização Econômica da Amazônia (SPVEA) em 1953, o segundo órgão regional a atuar no país. Era a primeira vez, desde a crise da borracha, ainda nos anos 1910, que uma ação planificada da União tentava fortalecer e dar nova feição à Amazônia como um todo, e não somente revitalizar a economia gomífera. $\mathrm{O}$ artigo tem por finalidade esclarecer de que maneira a SPVEA tentou executar seu objetivo, ou seja, a reestruturação da sociedade amazônica. Foram inúmeros os problemas que a instituição encontrou em sua trajetória. Após estabelecer como a SPVEA foi criada e comentar brevemente sobre seus objetivos, a ênfase encontra-se em dois pontos cruciais que são praticamente ignorados na pequena bibliografia sobre o tema: primeiro, trazer à tona o trabalho dos superintendentes, principalmente as dificuldades enfrentadas, responsáveis por fazer com que quase todos desistissem do cargo. Em segundo lugar, apresentar o modo como se deu a total perda de confiança a respeito do trabalho da instituição, fazendo com que esta recebesse o rótulo de instituição corrompida.
\end{abstract}

Palavras-chave: Amazônia. Desenvolvimento regional. SPVEA.

\section{The developmental policy for the Amazon: implementation, objectives and the fall of SPVEA (1953-1966)}

\begin{abstract}
The federal government created the Superintendency of the Amazonian Economic Valorization Plan (SPVEA) in 1953, the second regional agency to operate in the country. It was the first time, since the rubber crisis in the 1910s, that a planned action by the Union sought to strengthen and reshape the Amazon as a whole, and not only to revitalize the rubber economy. The objective of the article is to clarify how the SPVEA tried to reach its goal, that is, the restructuring of the Amazonian society. There were numerous problems that the institution found in its trajectory. After establishing how SPVEA was created and commenting briefly about its objectives, the emphasis is on two crucial points that are almost ignored in the small bibliography on the subject: first, bring to light the work of the superintendents, especially the difficulties faced, responsible for to make almost all of them give up the job. Second, to present the way in which the total loss of confidence about the work of the institution occurred, causing it to receive the label of a corrupted institution.
\end{abstract}

Keywords: Amazon. Regional development. SPVEA.

Artigo recebido em 8 dez. 2018.

Aprovado em 27 mar. 2019.

\footnotetext{
* Bacharel pela Universidade Federal do Rio de Janeiro (2005), Mestre em História Social pela Universidade Federal do Amazonas (2017), doutorando pela Fundação Getúlio Vargas (RJ) - Programa de Pós-Graduação em História, Política e Bens Culturais. O presente trabalho foi realizado com apoio da Coordenação de Aperfeiçoamento de Pessoal de Nível Superior - Brasil (CAPES) - Código de Financiamento 001.
} 
Para compreender em que circunstâncias surgiu a Superintendência do Plano de Valorização Econômica da Amazônia (SPVEA) é preciso ter em mente que a partir do fim da década de 1940 e durante toda a década de 1950, o Brasil formulou programas de estímulo e recuperação das suas regiões menos desenvolvidas. O intuito de tal política, baseada na ideologia desenvolvimentista nacionalista ${ }^{1}$, era conseguir uma maior integração econômica nacional $e$ diminuir as diferenças sociais entre o Sudeste, mais próspero, e o restante do país. Para cumprir tais objetivos, o governo federal criou a SPVEA em 1953, cinco anos após a Comissão do Vale do São Francisco e seis anos antes da SUDENE (Superintendência do Desenvolvimento do Nordeste).

A partir do golpe que depôs o presidente Washington Luís, convencionado como Revolução de 1930, iniciou-se um progressivo aumento de poder do governo federal brasileiro. No período em que comandou o país (1930-1945) Vargas agiu, basicamente, de duas maneiras para centralizar o poder em suas próprias mãos: transferiu muitas funções administrativas, antes exercidas pelos governos estadual e municipal, para a competência federal e ampliou consideravelmente a intervenção federal na economia. Essas ações exigiram a criação de novas agências controladas diretamente pelo governo central que, por sua vez, enfraqueceram ainda mais o poder relativo dos estados e municípios. A partir da instauração do Estado Novo em 1937, Vargas conseguiu alcançar a implantação de um regime francamente autoritário e o Brasil passou, então, a possuir um governo nacional forte e centralizado. As decisões estratégicas tornam-se definitivamente competência do governo federal e em nenhum campo significativo os estados conseguiriam mais o poder de legislar. (Fausto, 2007, p. 135) A economia passaria a ser gerida cada vez mais por um constante aperfeiçoamento do intervencionismo da União. O Estado brasileiro se complexificava e modernizava e, nesse sentido, realizou um reordenamento institucional visando uma crescente estatização, com a hipertrofia do Executivo central. "Com a criação de novos órgãos e funções, ampliou-se o aparelho burocrático, com a deliberada incursão do Estado nos planos educacional, de saúde, habitação, ao mesmo tempo em que proliferaram empresas estatais e de economia mista" (Pesavento, 1994, p. 44).

O intervencionismo estatal introduziu uma grande alteração no quadro de instituições brasileiras e gerou um conjunto de agências planejadoras. Em 1945, após a queda de Vargas e a volta da democracia, o Brasil havia herdado um executivo federal muito mais atuante.

\section{A Amazônia}

A região era compreendida pelo governo federal como um grande problema a ser resolvido. Deficitária e dependendo cada vez mais das ações do governo central, era encarada 
como um risco para a soberania brasileira e à segurança do Estado. Assim, o desenvolvimento econômico do Norte e sua efetiva integração com o restante do país tornaram-se essenciais para fazer com que a Amazônia pudesse ter suas potencialidades desenvolvidas. Era necessário fazer com que a Amazônia alcançasse uma posição relevante, ainda que periférica, na nova dinâmica industrial brasileira.

O Discurso do Rio Amazonas, feito por Vargas em Manaus no ano de 1940, representa um marco simbólico do início da construção de uma nova estratégia governamental brasileira para a região. Passava a ser um dever do país resgatá-la da decadência em que se encontrava desde a crise do ciclo da borracha, nos primeiros anos da década de 1910. Para isso era necessário vencer a posição geográfica, responsável pelo seu isolamento físico, social e econômico.

Com elementos de tamanha valia, não mais perdidos na floresta, mas concentrados e metodicamente localizados, será possível, por certo, retomar a cruzada desbravadora e vencer, pouco a pouco, o grande inimigo do progresso amazonense, que é o espaço imenso e despovoado. É tempo de cuidarmos, com sentido permanente, do povoamento amazônico. Nos aspectos atuais, o seu quadro ainda é o da dispersão. [...] O nomadismo do seringueiro e a instabilidade econômica dos povoadores ribeirinhos devem dar lugar a núcleos de cultura agrária, onde o colono nacional, recebendo gratuitamente a terra desbravada, saneada e loteada, se fixe e estabeleça a família com saúde e conforto. [...] O vosso ingresso definitivo no corpo econômico da Nação, como fator de prosperidade e de energia criadora, vai ser feito sem demora. [...] (Vargas, 1940, p. 78-79).

Os anos 40 proporcionaram ainda grande visibilidade à questão amazônica por causa de dois eventos externos: a Segunda Guerra Mundial e a tentativa de implantação do Instituto Internacional da Hileia Amazônica.

Em 1942 foram assinados os Acordos de Washington, que garantiam aos Estados Unidos a exclusividade comercial sobre algumas matérias-primas brasileiras estratégicas, principalmente a borracha. Os americanos recorreram ao Brasil para evitar que sua economia de guerra fosse prejudicada pela perda da borracha asiática, já que os países produtores daquela região haviam sido invadidos pelo Japão. Para alcançar novamente uma grande produção de borracha, a União conseguiu levar do Nordeste para Belém, onde foram redistribuídos, mais de 32 mil trabalhadores e seus dependentes, somando 48 mil pessoas. Entretanto, os recém-chegados "soldados da borracha" estavam completamente despreparados para enfrentar o pesado trabalho de extração $e$ as condições de vida na floresta. Além disso, muitos se sentiram enganados pelas propagandas de incentivo à mobilização, feitas pelo governo federal, e recusaram-se a trabalhar ou abandonaram o serviço logo após a sua chegada (Mahar, 1978, p. 13). A intervenção governamental brasileira durante a Segunda Guerra injetou recursos e mão de obra em uma 
atividade que agonizava há décadas e apenas estimulou um ciclo social que já era considerado uma calamidade. O seringueiro continuou isolado de tudo e de todos, totalmente à mercê das vontades de seu patrão (Pinto, 1984, p. 10). O fracasso da empreitada fez com que os representantes da região no Congresso Nacional passassem a defender uma política de desenvolvimento amplo, mais completa e de longo prazo.

O segundo evento que chamou a atenção do país para a Amazônia foi a proposta de criação do Instituto Internacional da Hileia Amazônica (IIHA), em 1948. Esse fato gerou uma discussão muito grande em torno da questão do perigo da internacionalização da Amazônia e do receio de que o Brasil viesse a perder sua soberania sobre a região. A concepção do Instituto partiu do químico brasileiro, o professor Paulo Estevão de Berrêdo Carneiro, embaixador do Brasil junto à Organização das Nações Unidas para a Educação, a Ciência e a Cultura (UNESCO), função que exerceu de 1946 a 1958. O grande adversário do IIHA foi o ex-presidente Artur Bernardes, que firmou posição enérgica contra o projeto. $\mathrm{O}$ argumento mais forte de Bernardes era uma possível dominação imperialista sobre a Amazônia travestida de objetivos científicos (Petitjean e Domingues, 2000, 283). Como presidente da Comissão de Segurança Nacional, Bernardes solicitou um parecer do Estado Maior das Forças Armadas sobre o IIHA. O relatório do Estado Maior apontava que os países amazônicos não tinham qualquer vantagem ou preferência para exercer a direção do Instituto ou fazer parte da Comissão Executiva do IIHA, que daria lugar a apenas cinco dos seis países amazônicos integrantes (além de Brasil, Peru, Equador, Colômbia, Bolívia e Venezuela, também haveria mais três membros fundadores: França, Holanda e Itália). Ou seja, o Brasil poderia ter atuando em seu território uma instituição internacional sobre a qual não teria nenhum controle. $\mathrm{O}$ assunto foi encerrado, depois de muita polêmica, quando o Congresso Nacional suspendeu qualquer decisão sobre o tema (Petitjean e Domingues, 2000, p. 266).

\section{A lei e as intenções que visavam desenvolver a Amazônia}

Entre os dois eventos relatados acima ocorreu a promulgação da Constituição de 1946, que celebrava a volta da democracia após a queda de Vargas. Interessa-nos especificamente o artigo 199, proposto pelo deputado federal pelo Amazonas Leopoldo Peres, que criou o Plano de Valorização Econômica da Amazônia. Sucinto, o artigo apenas definia que a União aplicasse quantia não inferior a três por cento da sua renda tributária no desenvolvimento da área amazônica por, no mínimo, vinte anos consecutivos. Além da União, os estados e os territórios da região amazônica, bem como os respectivos municípios, também estavam obrigados a reservar 
para o mesmo fim, anualmente, três por cento das suas rendas tributárias (Baleeiro e Lima Sobrinho, 2012, p. 93).

Somente sete anos depois foi aprovada a lei $n^{\circ}$ 1.806, de 6 de janeiro de 1953, que esclarecia a natureza do Plano de Valorização da região e criava a Superintendência do Plano de Valorização Econômica da Amazônia (SPVEA). Em seu segundo artigo, a lei 1.806 estabelecia que, para fins de atuação da SPVEA, a Amazônia brasileira passaria a abranger a região compreendida pelos Estados do Pará, Amazonas, pelos territórios federais do Acre, Amapá, Guaporé (atual Rondônia) e Rio Branco (atual Roraima) e a parte do Estado de Mato Grosso a norte do paralelo de $16^{\circ}$, além da área do Estado de Goiás a norte do paralelo de $13^{\circ}$ e a área do Estado do Maranhão a oeste do meridiano de $44^{\circ}$ (área que passou a ser denominada como Amazônia Legal). Os recursos destinados à instituição só poderiam ser aplicados em medidas, serviços, empreendimentos ou obras que possuíssem fim estritamente econômico ou relação direta com a recuperação econômica da região, obedecendo à prioridade dos problemas regionais detectados pelos estudos conduzidos pela SPVEA. A Superintendência estava autorizada a promover acordos com os estados, municípios, autarquias, sociedades e entidades privadas compreendidas na área amazônica. Outro aspecto significativo da lei foi a definição da execução do Plano de Valorização por meio de planejamentos parciais, em períodos de cinco anos. Porém, o início dos trabalhos deveria ser realizado através de um Programa de Emergência até a aprovação final do primeiro planejamento quinquenal. A SPVEA foi criada com sede definida em Belém, mas para efeito da descentralização de serviços e maior agilidade na execução das obras planejadas, foi autorizada a manter divisões sediadas em Manaus e Cuiabá. Um aspecto fundamental da lei 1.806 estava presente no seu penúltimo artigo, o qual estabelecia como primeira prioridade a reforma e ampliação das centrais elétricas de Belém e Manaus (Brasil, 1953).

O projeto da Valorização da Amazônia foi classificado como empreendimento de grande porte e seus objetivos ficaram estabelecidos como um esforço nacional para assegurar definitivamente a ocupação territorial da Amazônia; construir na região uma sociedade economicamente estável e capaz de prover a execução de suas tarefas sociais; desenvolver a Amazônia num sentido complementar ao da economia brasileira (Superintendência do Plano de Valorização Econômica da Amazônia, 1954, p. 4).

O Primeiro Plano Quinquenal, que seria o guia responsável por toda a política de recuperação regional, foi produzido pela SPVEA para avaliar as necessidades da região. Foram apontados então sete problemas impeditivos do progresso da Amazônia: alimentação, produção de matérias-primas e sua industrialização, transporte, distribuição do capital, saúde, o nível cultural e o problema da recuperação das populações extrativistas. (Superintendência do Plano 
de Valorização Econômica da Amazônia, 1954, p. 5). Para começar a resolver essas questões, os planejadores da SPVEA dividiram a Amazônia em 28 zonas consideradas como imediatamente recuperáveis, usando critérios econômicos e políticos. A ideia era limitar a área espacial de enfrentamento dos problemas a proporções em que os mesmos pudessem ser superados através de projetos de aplicações práticas.

1) Belém-Bragança, 2) Manaus, 3) São Luiz, 4) Cuiabá, 5) Macapá, 6) Rio Branco (Acre), 7) Porto Velho, 8) Boa Vista (Rio Branco), 9) Santarém, 10) Marajó, 11) Altamira, 12) Tucuruí - Jatobal, 13) Itaituba, 14) Benjamin Constant, 15) Eirunepê, 16) Boca do Acre, 17) Campos de Puciari, 18) Parintins, 19) Tefé, 20) Uapês - Cucuí, 21) Vila Bittencourt (Rio Japurá), 22) Guajará - Mirim, 23) Cruzeiro do Sul, 24) Paranã (Alto Tocantins), 25) Bacia Rios Mearim e Pindaré, 26) Oiapoque, 27) Poxoréu, 28) Tocantinópolis. (Superintendência do Plano de Valorização Econômica da Amazônia, 1954, p. 5).

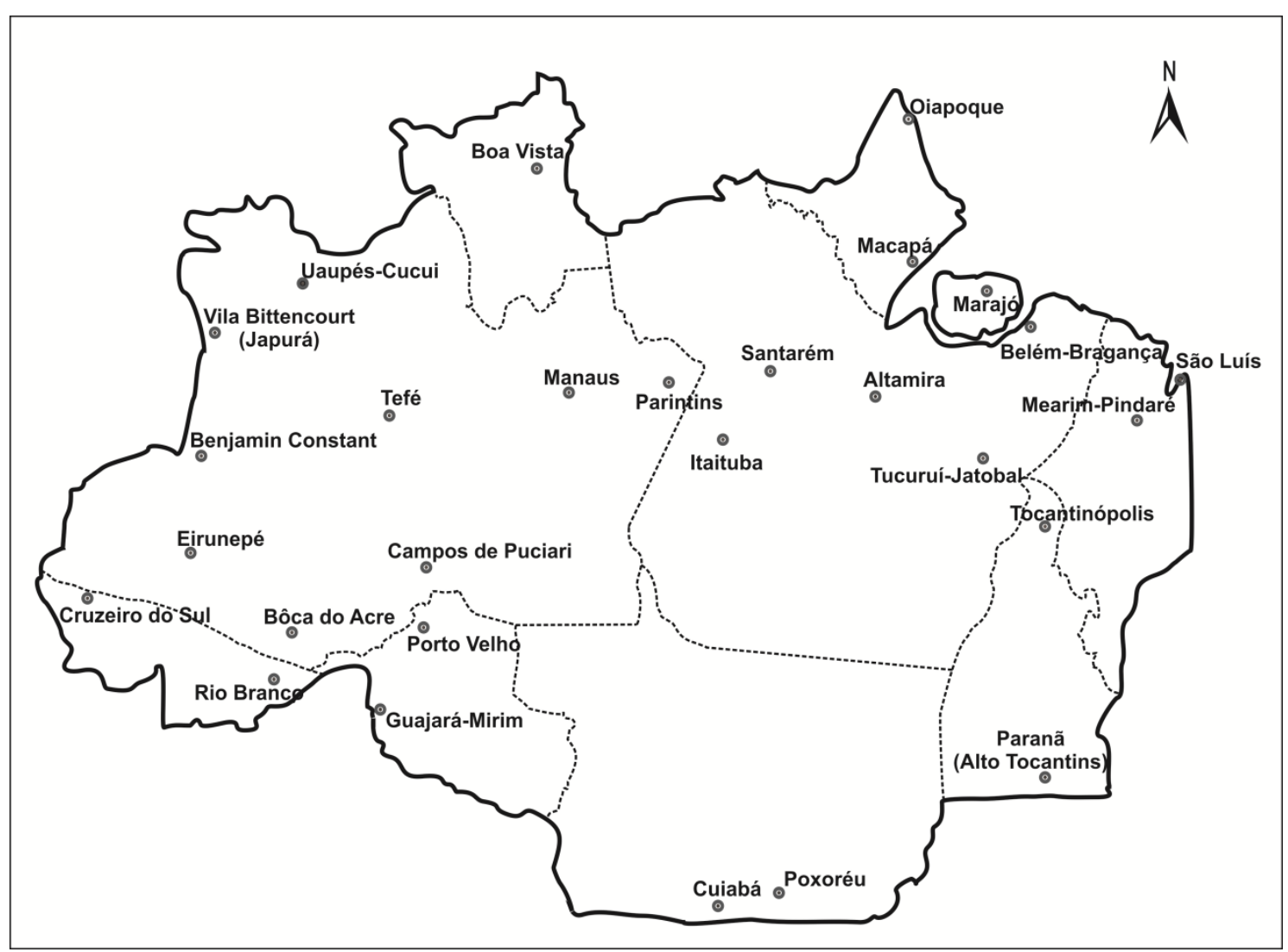

Figura 1 - Área de atuação da SPVEA (Amazônia Legal) com 28 zonas recuperáveis. ${ }^{2}$

O que é mais importante nesse planejamento é a visão adotada de que os problemas de base da Amazônia estavam interligados, não podendo ser entendidos e nem solucionados senão em conjunto. O Primeiro Plano Quinquenal formulou estratégias para superar todas as dificuldades apresentadas. Bem resumidamente, a intenção era investir de forma intensa no desenvolvimento da agricultura, acompanhada de uma política de colonização; além disso, 
incentivar a produção de carne bovina; implantar um sistema eficiente de transporte fluvial e construir rodovias; executar um amplo programa de saúde; incentivar o comércio das matérias-primas locais e ampliar a distribuição de recursos financeiros a quem quisesse investir na região. No entanto, apesar de sua extrema importância e de todos os estudos iniciais conduzidos pela SPVEA, as ações do Primeiro Plano Quinquenal não puderam ser implementadas. Ele nunca chegou a ser votado nas casas do Congresso Nacional, ficando esquecido até a extinção da Superintendência em 1966. Sem a sua aprovação, os investimentos nas 28 áreas mencionadas jamais saíram do papel.

\section{Os superintendentes}

Em seu período de treze anos de existência, a SPVEA teve sete superintendentes e um interventor, o que já demonstra que o trabalho não caminhou como deveria. Eis o tempo que cada dirigente ficou à frente da instituição:

\begin{tabular}{cc}
\hline Superintendente & Início - Fim \\
\hline Arthur Cezar Ferreira Reis & $01 / 08 / 1953-12 / 12 / 1955$ \\
Waldir Bouhid & $14 / 12 / 1955-31 / 01 / 1961$ \\
Aldebaro Cavaleiro de Macedo Klautau & $01 / 04 / 1961-19 / 09 / 1961$ \\
Mário da Silva Machado & $20 / 09 / 1961-25 / 10 / 1961$ \\
Mário Dias Teixeira & $30 / 10 / 1961-28 / 03 / 1963$ \\
Francisco Gomes de Andrade Lima & $29 / 03 / 1963-06 / 04 / 1964$ \\
Ernesto Bandeira Coelho (período de intervenção) & $07 / 04 / 1964-03 / 06 / 1964$ \\
Mário de Barros Cavalcanti & $04 / 06 / 1964^{*}-27 / 03 / 1967^{* *}$ \\
\hline
\end{tabular}

Tabela 1 - Tempo de cada superintendente à frente da SPVEA (Sudam, 2003, p. 1).

* A solenidade de posse ocorreu em 19 de maio de 1964, porém o início das atividades à frente da instituição se deu a partir de 04 de junho.

** Mário Cavalcanti deixou o cargo já como Superintendente da SUDAM, instituída no ano anterior ${ }^{3}$.

Focaremos a seguir na maneira como cada um deles tentou executar o projeto de ação desenvolvimentista para a Amazônia.

\section{Arthur Reis (08/1953 - 12/1955)}


Reis sempre foi cuidadoso no sentido de lembrar que o projeto era de longo prazo e que não podiam ser esperadas grandes obras e realizações logo. Essas estariam previstas para um momento posterior, no qual o conhecimento sobre a região estivesse mais completo. Apesar disso, a SPVEA começou a sofrer resistências e pressões desde muito cedo, principalmente por causa do atraso nos pagamentos dos convênios assinados para execução de obras e serviços. Arthur Reis, confirmando a demora na liberação das quantias demandadas, explicava da seguinte maneira a burocracia necessária para que fossem efetuados os pagamentos:

O que ocorre é que, de acordo com os próprios convênios, os pagamentos se processam em parcelas, geralmente quatro. A primeira paga no ato da assinatura, $e$ a segunda em data convencionada; a terceira $e$ a quarta, porém, somente depois de examinadas e aprovadas as contas relativas aos primeiros pagamentos. O processo pode ser lento e difícil, mas é seguro (Jornal do Comércio, 1955, p. 1).

Ignorando a primeira fase destinada à pesquisa científica e a intenção da SPVEA de iniciar suas ações em pontos e locais já predeterminados, os políticos e chefes dos estados $e$ municípios amazônicos pressionavam tanto a União quanto a Superintendência para resolver seus problemas internos, na tentativa imediatista de aumentar o próprio poder e influência local. O constante embate entre o que era planejado pela Superintendência e o que era desejado pelas elites locais levou Arthur Reis a deixar o cargo no final de 1955. Desgastado, Reis afirmou que sua saída foi causada "por exigência dos políticos", cujos desejos e interesses não quis atender (Reis, 1961).

\section{Waldir Bouhid (12/1955 - 01/1961)}

O segundo dirigente da SPVEA foi o grande personagem da instituição. Sua administração ficou marcada por escândalos de corrupção e desvio de dinheiro público. Mineiro, Waldir Bouhid era médico sanitarista e não um administrador de carreira, porém tornou-se um dos expoentes da administração Juscelino Kubitschek, sendo o responsável pelos primeiros anos de construção da rodovia Belém-Brasília. Bouhid já havia sido deputado estadual pelo Partido Social Democrático (PSD), presidente da Assembleia Legislativa no Pará e prefeito de Belém entre 1949 e 1950 .

No ano de 1957, denúncias do deputado Coaracy Nunes (PSD/Território do Amapá) sobre irregularidades na SPVEA resultaram na abertura de uma Comissão Parlamentar de Inquérito (CPI) para investigar malversação dos recursos atribuídos ao órgão federal, além de 
outras suspeitas na administração da Valorização entre 1954 e 1957. Em 30 de agosto, Coaracy Nunes deu depoimento à CPI declarando que a SPVEA exercia "um domínio econômico maléfico" à região amazônica em virtude da desorganização da instituição e do comportamento de Waldir Bouhid, que fazia política com os recursos destinados ao desenvolvimento regional. Nunes garantiu que existiam vários casos de pessoas que receberam somas elevadas por serviços de natureza técnica e científica de necessidade duvidosa, para os quais não estariam qualificadas. Por fim, o deputado disse que não tinha nada contra o antigo superintendente da SPVEA, Arthur Reis, a quem considerava um homem honrado (Jornal do Brasil, 1957a, 14). Apesar de a CPI abranger parte do período em que Arthur Reis esteve à frente da instituição, o alvo era Bouhid.

Após o começo das investigações, o Jornal do Brasil publicou uma matéria com o seguinte título: "Descalabro na SPVEA". Na matéria, o deputado federal pelo Amazonas, Riça Júnior, do Partido Trabalhista Brasileiro (PTB), apresentava sérias acusações contra a SPVEA:

[...] uma organização nos moldes daquela, que movimenta milhões e milhões de cruzeiros, sem contabilidade, ou, o que é pior, mantendo uma contabilidade deficiente e confusa, como se houvesse uma intenção preconcebida de balburdiar tudo (Jornal do Brasil, 1957b, 14).

A ex-poetisa e futura deputada Adalgisa Nery, dias antes, em sua coluna do periódico Última Hora, já havia censurado o comportamento do presidente Juscelino sobre o caso:

Todos sabem que o Sr. Valdir Bouhid está no pelourinho de uma Comissão de Inquérito Parlamentar, na qual é acusado de escândalos administrativos de aspectos muito feios e sem redenção. Como vai a suprema autoridade do país declarar à imprensa que o dito réu "conta com seu integral apoio pessoal"? (Nery, 1957, p. 3)

Em contraste com os jornais da capital federal, o Jornal do Comércio de Manaus enchia Bouhid de elogios, o que seria a tônica do periódico até o fim da SPVEA, qualquer que fosse o chefe da instituição.

Administrador consciente, capaz, dotado de alto espírito público e senso de responsabilidade [...] subordina seus atos num sadio desejo de acertar e de bem servir, sempre pautando seus atos por uma reta justiça. Chefe amigo, administrador capacitado de qualidades para o exercício de tão árduo mister, tem conseguido atravessar o superintendente Waldir Bouhid, com galhardia, todas as dificuldades encontradas em seu trabalho à frente da Valorização da Amazônia [...] (Jornal do Comércio, 1957, p. 6).

De fato, as elites amazônicas se sentiam excluídas e apequenadas em relação ao resto do país há muito tempo. As alegações que prejudicavam cada vez mais a reputação da Valorização da Amazônia eram vistas como tentativas de desestabilizar o trabalho feito na região e, principalmente, impedir o investimento no Norte, fazendo com que o dinheiro aplicado na região 
rumasse para outras atividades em outros estados do país. Os políticos amazônidas que participavam dos ataques à SPVEA eram muitas vezes tratados como traidores da Amazônia. Nesse sentido, o Jornal do Comércio de Manaus sempre teve um posicionamento nítido, atuando como propagador dos interesses políticos e econômicos do pensamento conservador das elites amazonenses.

Um setor que atraiu inúmeros ataques e desconfianças foi a Comissão Executiva da Rodovia Belém-Brasilia (Rodobrás), entidade criada dentro da estrutura administrativa da SPVEA e também comandada pelo seu superintendente. Em dezembro de 1958, a Rodobrás, em funcionamento há apenas seis meses, já era apontada como exemplo de corrupção pelo deputado estadual Ferro Costa, da União Democrática Nacional (UDN) do Pará. A importância da estrada, que unia a nova capital ao Norte do país, fazia com que sua construção fosse imprescindível para o governo federal. Por isso, a Belém-Brasília (também conhecida por Bernardo Sayão e BR-14, hoje BR-153) passou a ser prioridade para a SPVEA, o que causou um enorme alvoroço. Iniciada em agosto de 1958, logo foi alvo de questionamentos e contestações. Ferro Costa, por exemplo, anunciava que a SPVEA estava sendo dilapidada por negocistas $e$ grupos políticos e que a BR-14 seria a mais cara do mundo: "um quilômetro daquela rodovia está custando o dobro do preço que comumente se paga em outras regióes do país" (Correio da Manhã, 1959, p. 11; 14). Em fevereiro de 1960, o senador amazonense Antóvila Mourão Vieira, do PTB, afirmava que o dinheiro da região estava comprometido por causa da Belém-Brasília, pois após os cortes feitos pela União, havia sobrado para a SPVEA apenas a quantia de 500 milhões de cruzeiros para investimentos em toda Amazônia, enquanto estavam destinados 1 bilhão e 400 milhões de cruzeiros somente às obras da rodovia (Correio da Manhã, 1960, p. 6).

Bombardeado por críticas de todos os lados, Bouhid entregou a elaboração de um relatório de avaliação do desempenho da SPVEA a uma empresa privada de assessoria técnica: a Consórcio de Planejamento e Empreendimentos S/A, sediada no Rio de Janeiro. O curioso é o fato de a empresa ter tido apenas cinco meses para efetuar a análise de 7 anos de trabalho da SPVEA. A avaliação, que englobou o período entre 1954 e 1960, resumiu os fatores de limitação da eficiência da SPVEA em dois: os fatores intrínsecos (relacionados à estrutura do órgão) e os fatores extrínsecos (definidos pelas relações externas que a SPVEA mantinha com outras entidades).

Entretanto, de acordo com o Consórcio, os fatores que mais prejudicaram o andamento das ações da Superintendência foram os fatores extrínsecos, que estavam fora do alcance da instituição, principalmente os conflitos de competência entre a SPVEA, o Departamento Administrativo de Serviço Público (DASP) e o Congresso Nacional. O DASP era apontado como principal culpado pelos problemas que abrangiam os programas de desenvolvimento regional 
elaborados pela Valorização, pois interferia na orçamentação de forma ilegal, cortando ou alterando dotações e fixando prioridades à sua vontade. Continuando, o relatório alega que a execução das obras programadas pela Superintendência foi repetidamente frustrada desde a entrega das primeiras parcelas da cota constitucional, causando reflexos profundos. Essa indisciplina teve origem, sobretudo, nos planos de contenção de despesas públicas da União. Em decorrência disso, foi necessário abandonar centenas de trabalhos (que ficaram inacabados ou sequer começaram).

Apesar de toda dificuldade, a SPVEA foi avaliada como um fator de compensação, que impediu o agravamento do desequilíbrio econômico entre a região amazônica e o centro-sul do país através de algumas mudanças estruturais, como a maior presença da indústria e da agricultura na formação da riqueza social. O Consórcio enumerou as conquistas da Superintendência até então: ela foi responsável por inventários florestais, através de convênios com a UNESCO, para o conhecimento adequado da floresta e da utilidade das suas espécies, além de estudos para determinar a ocorrência de minerais no solo amazônico. Fomentou a produção e posterior distribuição de sementes e mudas, principalmente hevea brasiliensis (seringueira), arroz e juta. Comprou navios de passageiros e carga (embora em número reduzido para o tamanho da Amazônia) e criou cinco novas linhas de navegação, reestabelecendo outras quatro. Distribuiu livros didáticos impressos por conta própria e montou bibliotecas. Em relação ao capital privado, financiou fábricas e empresas de papel; exportação de produtos regionais; pesca, redes e sacaria; tecelagem, frigoríficos, gelo, transporte aéreo de passageiros e alimentos, artefatos de borracha etc. Todavia, por precisar operar primeiramente no domínio da pesquisa, a SPVEA não conseguiu executar realizações grandiosas e de ampla repercussão. Pará e Amazonas foram áreas preferenciais, com 23,7\% e 21,2\%, respectivamente, dos recursos aplicados pela SPVEA (Superintendência do Plano de Valorização Econômica da Amazônia, 1960a, passim).

Mesmo ressaltando os fatores externos como os principais causadores de problemas para a instituição, a empresa enxergava como necessária uma reformulação administrativa, na qual deficiências estruturais, funcionais e operacionais deveriam ser corrigidas. Ponto intrigante é que, após criticar a formação da Comissão de Planejamento da SPVEA por causa da participação de representantes políticos, o Consórcio ofereceu um novo modelo estrutural que estabelecia o Conselho de Planejamento, repetindo a mesma estrutura já existente e mantendo a participação dos representantes políticos escolhidos pelos estados amazônicos (Superintendência do Plano de Valorização Econômica da Amazônia, 1960b, p. 449). Essa contradição talvez seja explicada pelo fato de, durante o processo de análise, ter havido a percepção de que não seria possível afastar as influências regionais das decisões tomadas pela Superintendência. 
Por fim, o trabalho realizado pelo Consórcio não gerou nenhum impacto positivo sobre a situação da Superintendência e de seu chefe. Em um conjunto de artigos intitulados "E a Amazônia, senhor Presidente?", o jornalista e escritor Osório Nunes utilizou os dados expostos pelo trabalho de avaliação para criticar duramente o órgão e o governo federal. Em seus comentários, Nunes constrói um cenário amazônico deprimente e enumera os erros cometidos pelo país na condução da política da Valorização: a falta de um planejamento global, a displicência nos programas de energia, a ineficiência dos sistemas de transporte e de abastecimento de alimentos, o abandono dos seringais, entre outros (Nunes, 1961a, p. 13). Para o autor, houve desinteresse em relação a Amazônia e a tentativa de planejamento regional havia sido um fracasso até então: "é preciso remover os escombros do pseudoplanejamento que desabou na Amazônia [...]" (Nunes, 1961b, p. 12).

No decorrer de 1961, o Ministro da Justiça, Armando Falcão, pediu punição a Waldir Bouhid faltando apenas três dias para que este entregasse o cargo. O motivo do pedido foi a falta de resposta a respeito de dez documentos exigidos pelo Tribunal de Contas da União sobre a prestação de contas da SPVEA referente ao exercício de 1959. O Tribunal considerou insatisfatórios os documentos enviados como comprovantes de despesas diversas (Jornal do Brasil, 1961a, p. 5). Houve também uma sindicância instaurada pelo Presidente Jânio Quadros que acusava Bouhid de sumir com 4 bilhões da SPVEA, no que seria "o maior escândalo administrativo de que se tem notícia no país". O superintendente era responsabilizado de comprar e deixar abandonados 5 aviões e conceder empréstimos astronômicos a uma empresa de tecelagem do Maranhão (Correio da Manhã, 1961a, p. 12). Porém, o caso de maior repercussão foi a chamada Operação Bananal. Classificada como um empreendimento criminoso pelo Ministro da Justiça Pedroso Horta, foi o suposto emprego irregular de 350 milhões de cruzeiros sem dotação orçamentária própria para tal. O coronel reformado da polícia militar de Minas, Nélio Cerqueira Gonçalves e Waldir Bouhid foram acusados de serem os responsáveis (Correio da Manhã, 1961b, p. 8; 12). Alguns meses depois, o Ministro da Justiça Alfredo Nasser (a rotatividade no cargo foi grande em 1961) pediu a instauração de sete comissões de inquérito para apurar as irregularidades da gestão Bouhid. Segundo o Ministro, praticamente em todos os setores de atuação da instituição foram praticados abusos. Os piores eram: ausência de estudos técnico-econômicos na concessão de financiamentos, efetuados apressadamente e por pessoas sem qualificação técnica, ausência de fiscalização quanto à finalidade dada aos empréstimos, negligência no recebimento dos juros referentes aos empréstimos feitos, falta de prestação de contas, que deveria ser mensal, relativas às obras da Belém-Brasilia durante os anos de 1959, 1960 e 1961, num total de 5 bilhões de cruzeiros, valores milionários em contas particulares de funcionários da SPVEA, irregularidades em convênios e na aquisição e distribuição de tratores. 
Tudo estava sob suspeita. O Ministro concluiu apontando a administração da Valorização como "verdadeiramente ruinosa" (Jornal do Brasil, 1962a, p. 4). A resposta de Bouhid foi apresentar uma queixa-crime contra Nasser por este promover "a difamação através do sensacionalismo publicitário". Acusou ainda a sindicância de atuar com o objetivo de inventar irregularidades na sua administração para denegrir a obra de Juscelino Kubitschek através de seus auxiliares (Jornal do Brasil, 1962b, p. 4). Apesar do barulho, as sindicâncias e inquéritos iniciados no governo Jânio caíram no esquecimento. A falta de informações sobre o desfecho de cada uma delas nos levam a crer que foram arquivadas após a repentina ruptura ocorrida com a renúncia do Presidente e a posterior crise política que se instaurou sobre o governo de João Goulart. A primeira CPI contra a SPVEA, ainda no governo Kubitschek, também havia sido arquivada após perder força por causa da trágica morte do deputado Coaracy Nunes (falecido em acidente de avião em 21 de janeiro de 1958), já que este foi o autor da denúncia que deu origem à Comissão (Jornal do Brasil, 1958, p. 7).

\section{Aldebaro Klautau (04/1961 - 09/1961) e Mário Machado (09/1961 - 10/1961)}

O novo escolhido para chefiar a SPVEA assumiu em meio ao turbilhão que atingia em cheio a instituição. Aldebaro Klautau, professor e advogado paraense, já havia sido deputado estadual no Pará pelo Partido Social Progressista (PSP) e candidato a governador do mesmo estado em 1960. Segundo o Jornal do Comércio de Manaus, ao entrar na SPVEA, Klautau encontrou um legado de 1600 obras paralisadas. Para tentar resolver o problema, o novo superintendente procurou retomar as operações de maior interesse coletivo (Jornal do Comércio, 1961, p. 6). No fim de junho de 1961 aconteceu um encontro entre Klautau e os governadores do Amazonas, Pará e Amapá com o objetivo de se prepararem para conversar com o Presidente da República. Nessa reunião, o chefe da Valorização disse que estava encontrando sérias resistências em sua luta para deixar o orçamento da SPVEA livre das "injunções político-partidárias", fazendo um apelo para que os governadores o ajudassem. Acrescentou ainda que se houvesse qualquer corte de orçamento por parte da União, o que era comum acontecer, centenas de obras seriam interrompidas (Jornal do Brasil, 1961b, p. 4). Sem conseguir mudar o panorama vigente, Aldebaro Klautau pediu exoneração três meses após a reunião com os governadores amazônidas.

O General Mário Machado exerceu a função de chefia da Valorização da Amazônia como interino, ficando no posto apenas 35 dias.

\section{Mário Dias Teixeira (10/1961 - 03/1963)}


No período em que comandou a Superintendência, Mário Teixeira se esforçou para que houvesse uma reformulação, tanto do governo federal quanto da própria SPVEA, na maneira de conduzir a política direcionada à Amazônia. Considerando que o caminho seguido até então estava errado e não atendia à realidade da região, chegou a afirmar que sem o decidido $e$ decisivo apoio dos homens públicos do país e da região amazônica, o cargo que ocupava não lhe trazia nenhuma sedução (Jornal do Comércio, 1962a, p. 1). Incomodado com a fragmentação dos investimentos, trabalhou para que houvesse uma união maior entre os estados, na esperança de que enxergassem a região como um todo, para um aproveitamento mais racional dos investimentos. Providenciou a compra de um grande terreno para que fosse construída a sede da Superintendência, já que quase 10 anos após sua criação ainda não possuía sede própria (Jornal do Comércio, 1962b, p. 1). Durante sua temporada no órgão federal, teve que voltar suas atenções à Belém-Brasília, já que o governo do ex-presidente Jânio Quadros não teve interesse em investir na rodovia. Quadros inclusive já havia chamado a rodovia de "estrada para as onças" (Jornal do Brasil, 1959, p. 4). Nos anos de 1961 e 1962, o superintendente foi envolvido na desordem sobre a responsabilidade pela construção da estrada. O governo de Jânio Quadros, através do decreto $\mathrm{n}^{\circ} 50.272$, de 15 de fevereiro de 1961, transferiu a Rodobrás para o Departamento Nacional de Estradas de Rodagem (DNER). Um ano depois, pelo decreto $\mathrm{n}^{\circ} 628$, de 23 de fevereiro de 1962, João Goulart devolveu a Rodobrás à estrutura administrativa da SPVEA. A aplicação de dinheiro público na rodovia também foi alvo de uma CPI, que investigava o emprego dos recursos do Plano Rodoviário Nacional. As discordâncias entre a Valorização e o DNER levaram os responsáveis pelos dois órgãos a serem acareados (Correio da Manhã, 1962, p. 7). Porém, é importante salientar que o desvio de maquinário ocorreu durante o período em que a Belém-Brasília ficou sob responsabilidade do DNER. Depois do retorno da Rodobrás à SPVEA, as obras de recuperação foram retomadas.

No entanto, não conseguindo avançar em sua intenção de implantar um novo Plano Diretor e nem evitar os cortes bilionários no orçamento da Superintendência, Teixeira, completamente frustrado, exonerou-se. Ao passar suas atribuições a Andrade Lima, qualificou a SPVEA como um órgão inutilizador de homens e destruidor de ideais (Jornal do Comércio, 1963a, p. 8).

\section{Francisco de Andrade Lima (03/1963 - 04/1964)}

Nomeado por João Goulart, o engenheiro Andrade Lima era um homem desconhecido na região amazônica. Sua escolha desagradou toda a bancada da Amazônia na Câmara Federal, que desaprovou o seu nome exatamente pela falta de vínculo com a região (Jornal do Comércio, 
1963b, p. 8.). Chegando à chefia do órgão em um momento em que era impensável a continuação dos seus trabalhos sem uma reformulação, Andrade Lima contou com o apoio integral de Goulart para elaborar um novo plano que modificasse o aparentemente inalterável perfil amazônico.

Um dos pontos que seriam revistos era o da economia gomífera. Em 1963, a Valorização era acusada de nada fazer em favor da borracha: "A SPVEA cruzou os braços e nunca deu maior atenção ao problema, o que fez com que os seringueiros que lá trabalham, na sua maioria, ficassem entregues à própria sorte por falta de assistência técnica e material" (Carvalho, 1963, p. 4). A visita do Ministro da Agricultura, Ermírio de Moraes, ao Amazonas jogou mais pressão sobre a Superintendência. Moraes se disse chocado ao observar a situação em que se encontravam os trabalhadores da borracha e da juta, afirmando inclusive que as condições de trabalho eram piores do que no tempo da escravidão. Segundo o Ministro, quase nada havia sido feito pelos órgãos responsáveis até então (Jornal do Brasil, 1963, p. 9).

Apesar de tudo, Andrade Lima começou o ano de 1964 recebendo elogios de deputados da Amazônia pelas boas condições da rodovia Belém-Brasilia. O chefe da Valorização encontrou-se com os parlamentares na Comissão Financeira da Câmara Federal para apresentar o seu Plano de Ação na Amazônia, previsto para ser executado em dois anos. Os deputados amazônicos presentes mostraram-se satisfeitos com o trabalho feito por Lima, congratulando-o por seus esforços (Última Hora, 1964, p. 3). Entretanto, mesmo com o empenho de Andrade Lima, um mês depois da exposição de seu projeto na Câmara Federal, a SPVEA recebia como interventor o General Ernesto Bandeira Coelho (04/1964 - 06/1964), colocado pelo governo golpista para apurar as irregularidades da instituição. Durante o período de intervenção, todos os trabalhos do órgão federal ficaram paralisados. Em seguida, o também general de divisão Mário de Barros Cavalcanti assumiu a direção da Superintendência, com esta passando à responsabilidade do recém-criado Ministério Extraordinário para a Coordenação dos Organismos Regionais.

\section{Mário Cavalcanti (06/1964 - 03/1967)}

Num primeiro momento houve a tentativa de recuperar a SPVEA, fazendo com que esta passasse a ser vista como uma instituição renovada e confiável. Por isso, o foco inicial foi a sua reestruturação interna. Em seguida, foram tomadas medidas de descentralização pelo superintendente, já que até então tudo era resolvido apenas na sede em Belém. Essa medida era reclamada há bastante tempo, pois era preciso enviar representantes ou manter um procurador somente para receber as verbas da instituição. Mário Cavalcanti também inaugurou a sede da 
Superintendência em Belém, que finalmente teria seus funcionários trabalhando juntos, em vez de espalhados em mais de uma dezena de prédios públicos (Jornal do Comércio, 1966, p. 5).

Porém, o período de reformulação dos militares não foi isento de críticas. No início de 1965, o Governador do Acre, Edgard Cerqueira, pedia a extinção da SPVEA, alegando que esta não atendia ninguém e muito menos a Amazônia (Jornal do Comércio, 1965b, p. 3). No Jornal do Comércio amazonense a SPVEA também recebia críticas, pois era vista como uma distribuidora "de verbas inúteis e contraproducentes que jamais deram rendimento à região" (Jornal do Comércio, 1965c, p. 5). O mesmo artigo também condenava os políticos nortistas, alegando que estes não colocavam a Amazônia acima de seus interesses pessoais. Esse foi um dos raros ataques do jornal ao trabalho da Valorização.

Por fim, quando o governo civil-militar resolveu encarar os problemas da Amazônia de maneira mais objetiva, o fez colocando em vigor a Lei $n^{\circ} 5.173$, de 27 de outubro de 1966, que extinguiu a SPVEA e criou a Superintendência do Desenvolvimento da Amazônia (SUDAM). A substituição da SPVEA pela SUDAM foi um dos pilares da Operação Amazônia, um conjunto de instrumentos legais, adotados entre os últimos meses de 1966 e o início do ano seguinte. Essa operação regulamentou a Zona Franca de Manaus, criando sua Superintendência e o Banco da Amazônia, que substituiu o Banco de Crédito da Amazônia.

\section{Os motivos para a extinção da SPVEA}

A SPVEA, desacreditada há anos, passava a imagem de um órgão inoperante e corrupto. Militares, políticos e imprensa convergiam para a mesma conclusão: a Superintendência não havia conseguido alterar em nada a fisionomia econômica da Amazônia. Entre 1964 e 1966, o superintendente militar Mario Cavalcanti produziu relatórios destacando todos os aspectos negativos que se acumulavam sobre a SPVEA e que geravam um clima constante de permissividade e ilicitude:

Tal clima permitiu toda sorte de desmandos, tais como: desvios de verbas, favoritismos políticos, regionalismo estadual e municipalista, ascensão de grupos inescrupulosos, concessões graciosas, empreguismo, investimento desordenado de recursos, inoperância administrativa, desfalques, enfim, um vasto campo de negociatas e irresponsabilidades sob as mais variadas formas (Cavalcanti, 1967, p. 46).

Onze anos após a sua criação, a SPVEA ainda não possuía um corpo de técnicos capazes de fazê-la alcançar seus objetivos. Cavalcanti afirma que em 1964 existiam no quadro de pessoal da instituição apenas 34 funcionários com nível técnico-científico, enquanto 581 funcionários 
exerciam atividades burocráticas (Cavalcanti, 1967, p. 39). Ao contrário do Consórcio em 1960, os militares enxergavam que o seu principal problema era interno:

[...] o insucesso verificado não resultou da escassez, frequentemente invocada, de recursos federais entregues à Região, pois sobem à centenas de bilhões de cruzeiros [...]. Também, não se pode atribuí-lo à falta de tentativas de planejamento, de vez que, nesse terreno, algumas iniciativas foram registradas, a começar com o Primeiro Plano Quinquenal, de 1955, jamais implantado. Por último, seria igualmente incorreto ignorar os bem intencionados esforços no campo da pesquisa agronômica e de recursos naturais da Região, assim como desconhecer que a SPVEA, órgão central da pretendida valorização, contou por vezes com administradores competentes e interessados. [...] (Cavalcanti, 1967, p. 656-657).

Apesar do discurso oficial do regime civil-militar negar que o insucesso da SPVEA se devia à falta de recursos federais, o próprio superintendente do órgão, diversas vezes nas avaliações contidas em seus relatórios, apontou o problema da falta de dinheiro como sendo o principal enfrentado pela instituição. Segundo Cavalcanti, os entraves ao bom funcionamento da SPVEA, nos anos de 1964 e 1965, eram os mesmos que já estavam presentes praticamente desde o seu nascimento. Vejamos:

a) A SPVEA funcionava como uma grande agência pagadora, com seus recursos manipulados por grupos interessados em fazê-la instrumento de prestígio local; havia centralização exagerada de poderes nas mãos do superintendente, que resolvia e decidia tudo.

b) Enquanto as obrigações aumentavam, os recursos diminuíam e Cavalcanti chega a levantar a hipótese de que o objetivo seria liquidar, definitivamente, a instituição. A crise financeira chegou a tal ponto que essa questão reduziu todas as demais deficiências da Superintendência a segundo plano. A SPVEA não conseguia competir com salários e melhores condições de vida em outras regiões, que acabavam atraindo os trabalhadores mais qualificados. Em relação aos três por cento constitucionais, os critérios de cálculo, ao longo dos anos, foram os mais variados. Ou calculava-se tomando-se por base a estimativa da receita prevista para o ano seguinte, ou a arrecadação do exercício anterior, ou ainda a receita esperada para o ano corrente. Pouquíssimas unidades políticas amazônicas saldaram seus compromissos para com a Superintendência (Cavalcanti, 1967, passim).

Em 14 de junho de 1965, o superintendente afirmava que a SPVEA não havia recebido, "até o presente, mesmo já estando a expirar o primeiro semestre, um duodécimo sequer do orçamento" (Cavalcanti, 1967, p. 315). Mário Cavalcanti também mostrava inconformidade com a desigualdade de tratamento dado à Valorização da Amazônia. Em comparação com o ano anterior, o orçamento da SUDENE em 1965 teve um aumento de 93,8\%. O orçamento da Comissão do Vale do São Francisco cresceu 34,8\%. Já a SPVEA recebeu irrisórios 0,05\% a mais, 
contrastando com suas despesas, aumentadas em 300\% (Cavalcanti, 1967, p. 132). Em 1966, para obedecer ao programa de cortes do governo federal, o orçamento da SPVEA foi reduzido em 20\% (Cavalcanti, 1967, p. 628).

Uma questão para a qual não encontramos explicação diz respeito a um empréstimo internacional feito pela SPVEA, algo que nunca havia sido permitido, apenas um mês antes de sua extinção e substituição pela SUDAM. O empréstimo foi feito com a Selective Investiments, de Nova York, no valor de 80 milhões de dólares, pagáveis em 13 anos, com taxa de juros de 7,5\% no primeiro ano e 8\% nos anos restantes (Cavalcanti, 1967, p. 647-648). Se o governo civil-militar assegurava que o insucesso da Superintendência não era resultado da escassez de recursos federais, fica difícil compreender a necessidade da transação.

Em relação aos feitos da instituição em seus últimos anos de funcionamento, a SPVEA concentrou seus recursos no setor de transportes e comunicações. O objetivo principal do órgão era finalizar a pavimentação da Belém-Brasilia. Sobre o trabalho realizado referente às empresas de energia elétrica dos estados amazônicos (um dos pontos cruciais da lei 1806), a conclusão era a de que a ajuda da SPVEA serviu apenas para evitar o colapso do seu normal funcionamento ou o fracasso das obras de empreendimentos em início de construção. Em discurso proferido em 31 de agosto de 1966, por ocasião de visita do Presidente da República, o superintendente elencou as realizações da SPVEA a partir de 1964: a descoberta de um novo e rico distrito ferrífero no estado do Amazonas, a localização de grandes reservas de calcário nas margens da Belém-Brasília e de sal-gema no Maranhão, além da comprovação científica de que o solo amazônico possuía condições ideais para o cultivo das oleaginosas (Cavalcanti, 1967, p. 377).

\section{Considerações finais}

A SPVEA tornou-se um fardo para a administração pública brasileira assim que o Primeiro Plano Quinquenal foi concluído, em 1954, sendo relegada à indiferença por todos os governos federais que se seguiram. O trabalho realizado pela SPVEA, durante as décadas de 1950 e 1960, foi insuficiente basicamente por dois motivos principais: o total descumprimento da obrigação constitucional de destinar o mínimo de três por cento da renda tributária para a Amazônia e a não aprovação do Primeiro Plano Quinquenal. A essas duas razões acrescentamos a construção da rodovia Belém-Brasília, que funcionou como um verdadeiro sorvedouro das verbas destinadas à Amazônia Legal.

A não aprovação do Primeiro Plano Quinquenal foi gravíssima para as pretensões da SPVEA, pois impediu que o órgão pudesse estabelecer qualquer planejamento de médio ou longo prazo. Sem se apoiar em um projeto claro e definido e sem poder contar com um conjunto 
de operações já previamente programadas, a Superintendência transformou-se em uma distribuidora de recursos financeiros e uma fazedora de convênios e acordos individuais. Sua atuação tornou-se fragmentada e ampla demais. Outro resultado da ausência de um programa duradouro em que a SPVEA pudesse se basear foi a descontinuidade dos trabalhos dos superintendentes. Sempre que existiram mudanças na direção do órgão, os novos responsáveis procuraram mudar a fisionomia da instituição, estabelecendo novos planos de trabalho $e$ a reformulação na aplicação de verbas e execução de convênios e obras. A falta de pagamento desestabilizou completamente os esforços da Superintendência, já que comprometeram o prosseguimento dos acordos firmados pela instituição, deixando obras inacabadas durante anos e interferindo no repasse aos estados e municípios.

As atitudes da União ao longo dos anos nos fazem concluir que o investimento em um espaço geográfico tão amplo e historicamente afastado da economia nacional era visto como improdutivo. Os altos custos para levar adiante o programa estabelecido não seriam compensados em um curto prazo de tempo. O fato é que nem na época do auge do extrativismo gomífero a economia amazônida teve um vínculo forte com o resto do país. Pelo contrário, sempre teve laços econômicos mais estreitos com a Europa. Em crise, a Amazônia dependia muito mais do contato com as outras regiões do país do que o contrário. Nem a borracha fazia falta às indústrias brasileiras, que importavam o produto a preços mais baixos. As complexas questões amazônicas passaram a ser consideradas obstáculos grandes demais para serem enfrentados. E se o governo federal não estava disposto a investir na estruturação da região, menos ainda estava o capital privado, que não via motivos para entrar em tamanha empreitada. Por isso, entre 1955 e 1966, a SPVEA foi "empurrada com a barriga" até encontrar o seu fim.

Dito isso, convém salientar que a instituição não deve ser eximida de responsabilidade sobre suas operações. Havia falhas internas graves, como a enorme burocracia; a estruturação da Comissão de Planejamento, que permitia a ingerência política no principal setor do órgão, e a falta de organização básica, principalmente sobre o controle financeiro e a fiscalização dos trabalhos realizados. A própria Superintendência também foi responsável por manchar sua imagem através de grandes escândalos nacionais e seguidas denúncias de corrupção, que durante anos alimentaram o imaginário de que a SPVEA era um antro de falcatruas, comandado por corruptos da pior espécie. Não foram os militares que imputaram o rótulo de falência moral $e$ órgão corrompido à SPVEA, a fama já tinha se estabelecido anos antes do golpe. Porém, vale lembrar que praticamente todas as denúncias se deram durante o período de Waldir Bouhid à frente do órgão e que nada foi provado contra o superintendente.

A SPVEA não conseguiu concretizar nenhum dos grandes objetivos que se propôs a realizar, a começar pelo que deveria ser a sua prioridade: a reforma e ampliação das centrais 
elétricas de Belém e Manaus. No entanto, mesmo a aplicação reduzida de verbas nos setores citados foi responsável para que houvesse, pelo menos, a disponibilidade dos serviços na região, por mais precários que fossem. O mérito da SPVEA foi colaborar para que houvesse algumas melhorias e relativo desafogo principalmente no Pará e Amazonas. Bem ou mal, ela foi responsável pelo primeiro planejamento de grande porte feito exclusivamente sobre os problemas amazônicos. As pesquisas foram estimuladas e continuaram com o tempo, reunindo um valioso material.

\section{Referências}

BALEEIRO, Aliomar; LIMA SOBRINHO, Barbosa. Constituições Brasileiras Vol. V: 1946. 3 ed. Brasília: Senado Federal, Subsecretaria de Edições Técnicas, 2012.

BIELSCHOWSKY, Ricardo. Pensamento econômico brasileiro: o ciclo ideológico do desenvolvimentismo. 4 ed. Rio de Janeiro: Contraponto, 2000.

BRASIL. Lei no 1.806, de 6 de janeiro de 1953. Dispõe sobre o Plano de Valorização Econômica da Amazônia, cria a superintendência da sua execução e dá outras providências. Diário Oficial da Uniãc, Rio de Janeiro, 7 jan. 1953.

CARVALHO, Augusto César. Brasil: Cinquenta milhões de dólares com exportação de produtos de borracha. Caderno Especial. Jornal do Brasi, Rio de Janeiro, 7 abr. 1963.

CAVALCANTI, Mário de Barros. Da SPVEA à SUDAM: (1964-1967). Belém: Sudam, 1967.

CORREIO DA MANHÃ. Comissão diz que Bouhid sumiu 4 bilhões da SPVEA. Rio de Janeiro, 26 abr. 1961a, $1^{\circ}$ Caderno.

CORREIO DA MANHÃ. Congresso Nacional. No Senado. Críticas à SPVEA, Rio de Janeiro, 16 fev. 1960, $1^{\circ}$ Caderno.

CORREIO DA MANHÃ. Nas Comissões. Belém-Brasília. Rio de Janeiro, 27 jun. 1962, 1 Caderno.

CORREIO DA MANHÃ. Sentença aponta irregularidades na SPVEA e na F. Brasil-Central. Rio de Janeiro, 18 ago. $1961 \mathrm{~b}, 1^{\circ}$ Caderno.

CORREIO DA MANHÃ. Será a mais cara do mundo a rodovia Belém-Brasília. Rio de Janeiro, 22 set. 1959, $1^{\circ}$ Caderno.

FAUSTO, Boris (dir.) O Brasil Republicano, v. 10: Sociedade e Política (1930-1964). 9a ed. Rio de Janeiro: Bertrand Brasil, 2007. 
JORNAL DO BRASIL. Bouhid diz que processa Nasser porque divulgou irregularidades na SPVEA. Rio de Janeiro, 23 jan. 1962b, 1 Caderno.

JORNAL DO BRASIL. Colonização e crédito são os temas da Amazônia no encontro com o Presidente. Rio de Janeiro, 22 jun. 1961b, 1 Caderno.

JORNAL DO BRASIL. Criado Grupo de Trabalho para estudar situação dos trabalhadores da borracha. Rio de Janeiro, 15 maio 1963, $1^{\circ}$ Caderno.

JORNAL DO BRASIL. Descalabro na SPVEA. Rio de Janeiro, 27 nov. 1957b, 1º Caderno.

JORNAL DO BRASIL. Líder da UDN explica: por que os comunistas preferem o PTB. Rio de Janeiro, 11 set. 1958, 2 Caderno.

JORNAL DO BRASIL. Ministro da Justiça pede punição funcional para o Superintendente da SPVEA. Rio de Janeiro, 29 jan. 1961a. $1^{\circ}$ Caderno.

JORNAL DO BRASIL. Nas Comissões. Rio de Janeiro, 31 ago. 1957a, $1^{\circ}$ Caderno.

JORNAL DO BRASIL. Nasser pede sete inquéritos para irregularidades na gestão Bouhid na SPVEA. Rio de Janeiro, 20 jan. 1962a, 1 Caderno.

JORNAL DO BRASIL. Rodovia Belém-Brasília é uma estrada para as onças diz Jânio Quadros. 24 fev. 1959, $1^{\circ}$ Caderno.

JORNAL DO COMÉRCIO. A Amazônia e o Orçamento da União. Manaus, 8 ago. 1965c.

JORNAL DO COMÉRCIO. Através de um plano de prioridade, SPVEA dará prosseguimento às obras paralisadas. Manaus, 28 jun. 1961..

JORNAL DO COMÉRCIO. De Frente de Perfil - Distribuidora de Homens. Manaus, 12 abr. $1963 a$.

JORNAL DO COMÉRCIO. Economia, Perspectivas \& Informações. Manaus, 20 jun. 1965a.

JORNAL DO COMÉRCIO. Festejará a DM. 1 do SPVEA o $2^{\circ}$ ano de administração de Waldir Bouhid. Manaus, 14 dez. 1957.

JORNAL DO COMÉRCIO. Governador do Acre diz que a SPVEA deve ser extinta. Manaus, 9 fev. 1965b.

JORNAL DO COMÉRCIO. Grandes problemas da Amazônia, Manaus. 11 fev. 1955. 
JORNAL DO COMÉRCIO. Interessado o Deputado José Esteves em valorizar os nossos produtos e industrializar a hinterlândia. Manaus, 15 jun. 1963b.

JORNAL DO COMÉRCIO. Novas instalações da SPVEA. Palavras do titular do órgão na solenidade de inauguração. Manaus, 7 jun. 1966.

JORNAL DO COMÉRCIO. Sede para a SPVEA. Manaus, 23 maio 1962b.

JORNAL DO COMÉRCIO. Superintendente do PVEA mobiliza opinião pública em defesa dos nossos interesses. Manaus, 22 de novembro de 1962a.

MAHAR, Dennis J. Desenvolvimento econômico da Amazônia: uma análise das políticas governamentais. Rio de Janeiro: IPEA/INPES, 1978.

NERY, Adalgisa. Autoridade e Irreflexão. Última Hora, Rio de Janeiro, 12 nov. 1957.

NUNES, Osório. E a Amazônia, senhor Presidente? De como se abandona um Império. Correio da Manhã, Rio de Janeiro, 30 maio 1961a. $1^{\circ}$ Caderno.

NUNES, Osório. E a Amazônia, senhor Presidente? Um plano tateante. Correio da Manhâ, Rio de Janeiro, 4 jun. 1961b, $1^{\circ}$ Caderno.

PESAVENTO, Sandra Jatahy. O Brasil contemporâneo. 2 ed. Porto Alegre: Editora da Universidade/UFRGS, 1994.

PETITJEAN, Patrick; DOMINGUES, Heloisa M. Bertol. A redescoberta da Amazônia num projeto da Unesco. Estudos Históricos. Rio de Janeiro: v.14, n.26, p. 265-292, 2000.

PINTO, Nelson Prado Alves. Politica da borracha no Brasil: a falência da borracha vegetal. São Paulo: Hucitec, 1984.

REIS, Arthur Cézar Ferreira. Prefácio. In: FERREIRA FILHO, Cosme. Amazônia em novas dimensões. Manaus: Conquista, 1961.

SUDAM. Relação dos superintendentes desde a sua fundação - SPVEA/SUDAM. Disponível em: http://www.sudam.gov.br/conteudo/menus/acessoainformacao/institucional/arquivos/relacao_superintendentes_ desde_a_sua_fundacao_spvea. Acessado em 09 out. 2018.

SUPERINTENDÊNCIA DO PLANO DE VALORIZAÇÃO ECONÔMICA DA AMAZÔNIA. Perspectiva do Primeiro Plano Quinquenal e Concep̧̧ão Preliminar da Valorização Econômica da Amazônia. Belém: Setor de Coordenação e Divulgação, 1954.

SUPERINTENDÊNCIA DO PLANO DE VALORIZAÇÃO ECONÔMICA DA AMAZÔNIA. SPVEA (1954/60). Politica de Desenvolvimento da Amazônia. v. 1. Rio de Janeiro: Gráfica Editora Livro S. A., 1960a. 


\section{SUPERINTENDÊNCIA DO PLANO DE VALORIZAÇÃO ECONÔMICA DA AMAZÔNIA. SPVEA}

(1954/60). Politica de Desenvolvimento da Amazônia. v. 2. Rio de Janeiro: Gráfica Editora Livro S. A., 1960 b.

ÚLTIMA HORA. Deputados Estão Coesos e Aplaudem Obras da SPVEA e Rodobrás na Amazônia. Rio de Janeiro, 7 mar. 1964.

VARGAS, Getúlio. O destino brasileiro do Amazonas. Disponível em:

http://www.biblioteca.presidencia.gov.br/presidencia/ex-presidentes/getulio-vargas/discursos/1940/31.pdf/view. Acessado em 09 out. 2018.

\footnotetext{
${ }^{1}$ Segundo Ricardo Bielschowsky, o desenvolvimentismo nacionalista foi uma ideologia econômica com fortes vínculos com o nacionalismo. Os desenvolvimentistas nacionalistas defendiam a constituição de um capitalismo industrial moderno no país. Entretanto, sua diferença em relação a outros grupos era a decidida defesa por uma ampliação cada vez maior da intervenção do Estado em setores estratégicos da economia.

2 Fonte: Mapa adaptado de SPVEA 1954/60 - Política de Desenvolvimento da Amazônia. v. 1

${ }^{3}$ Há divergência de datas entre o arquivo consultado e a obra Da SPVEA a SUDAM (1964-1967), de autoria de Mário de Barros Cavalcanti. Preferimos adaptar a tabela conforme as informações obtidas nas páginas 19 e 22 da obra de Cavalcanti.
} 